\title{
Marx e a crítica da religião ${ }^{1}$
}

Mauro Castelo Branco de Moura²

\section{Resumo:}

Trata-se de identificar os principais aspectos da análise de Marx sobre a crítica da religião desenvolvida na Alemanha à época. Para tanto, o autor analisa as várias indicações existentes a respeito do problema nos textos escritos por Marx de 1843 a 1844, sublinhando o caráter inédito no tratamento da questão religiosa, em contraste com aquele perpetrado pelos neo-hegelianos.

Palavras-chave: crítica da religião; neo-hegelianos; Marx; alienação.

\section{Marx and the critique of religion}

\begin{abstract}
:
The author intends to identify the main aspects about Marx's analysis of the critique of religion developed in Germany at the time. With this aim in mind, are discussed the several indications that existed in the texts written by Marx from 1843 to 1844, and is emphasized the unprecedented nature of the treatment of the religious question, in contrast with that perpetrated by the neo-Hegelians.
\end{abstract}

Key words: religion criticism; Neo-Hegelians Marx; alienation.

Marx, no artigo intitulado Zur Kritik der Hegelschen Rechtsphilosophie, Einleitung - redigido em dezembro de 1843 e publicado em Paris, no Deutsch-Französische J ahrbücher, no ano seguinte - começa sustentando a ideia de que "a crítica da religião é a premissa de toda a crítica" (MARX, 1982a, p. 491; 1959a, p. 207). Marx procura decifrar o religioso, o divino, a partir da realidade humana, influenciado pelas ideias de Feuerbach, para quem a religião seria a projeção da essência humana ou, em suas próprias palavras: "Deus não é outra coisa que a deidade ou divindade do homem personificada e representada como um ser" (FEUERBACH, 1972, p. 259). Com efeito, Feuerbach já havia

1 Trata-se do Capítulo III do livro Os mercadores, o templo e a filosofia: Marx e a religiosidade, publicado em 2004 pela Edipucrs de Porto Alegre.

2 Doutor, Professor Titular da Universidade Federal da Bahia (UFBA). E-mail: mcbmoura@ufba.br 
procurado mostrar que, por meio da religião, o homem aliena sua própria essência, delegando a outrem os atributos e potencialidades de si mesmo. Deus seria o próprio ser do homem objetivado como exterioridade ${ }^{3}$, daí que o conhecimento da realidade humana se devesse iniciar pela crítica da religião, modo primário de resgate da essência alienada do homem, desconhecida, estranhada de si mesma.

Não obstante, antes de afirmar a preeminência da "crítica da religião", Marx também afirma que "Na Alemanha, a crítica da religião chegou, no essencial, a seu fim" (MARX, 1982a, p. 500; 1959a, p. 207). Parece estar aqui subjacente a ideia de que, a despeito de seu atraso político com relação à França, e econômico com referência à Inglaterra, a Alemanha teria, talvez por isso mesmo, sublimado tais diferenças com um desenvolvimento filosófico superior ${ }^{4}$, assentado sobre a base de uma tradição teológica vigorosa, inaugurada com Lutero ${ }^{5}$. O fato é que a filosofia alemã assume um lugar de notório destaque com a Ilustração. A partir da Aufklärung, que tem em Kant, talvez, seu maior expoente, a Alemanha é içada à vanguarda em termos filosóficos. Apesar de sua confissão pietista, Kant, como é sabido, inviabiliza as demonstrações racionais da existência de Deus, que não poderia ser provado pela razão pura. Heinrich Heine, o famoso poeta, muito apreciado por Marx e, ademais, seu amigo6, no ensaio Zur Geschichte der Religion und Philosophie in Deutschland, publicado originalmente em 1834, chega a

3 Nas palavras de Feuerbach: "A religião é o comportamento do homem frente a seu próprio ser - nisto se baseia sua verdade e sua força saudável e moral -, porém a seu próprio ser não como se fora seu, senão como se fora de outro ser distinto dele e até contrário a ele - e nisto está fundada sua falta de verdade, seu limite, sua contradição com a razão e a moral." (FEUERBACH, 1972, p. 189)

4 "Assim como os povos antigos viveram sua pré-história na imaginação, na mitologia, assim nós, os alemães, vivemos nossa pós-história no pensamento, na filosofia. Somos contemporâneos filosóficos do presente, sem ser seus contemporâneos históricos." (MARX, 1982a, p. 495; 1959a, pp. 213-4)

5 "O passado revolucionário da Alemanha é, com efeito, um passado histórico: é a Reforma. Como então no cérebro do frade, a revolução começa agora no cérebro do filósofo. Lutero venceu, efetivamente, a servidão pela devoção, porque a substituiu pela servidão na convicção. Acabou com a fé na autoridade, porque restaurou a autoridade da fé. Converteu clérigos em seculares, porque converteu seculares em clérigos. Liberou o homem da religiosidade externa, porque erigiu a religiosidade no homem interior. Emancipou de cadeias o corpo, porque carregou de cadeias o coração." (MARX, 1982a, pp. 497-8; 1959a, pp. 217)

6 Segundo Franz Mehring, num contexto em que relata o período vivido por Marx em Paris, "Marx mantinha estreitas relações com Heinrich Heine e contribuiu com sua parte para que o ano de 1844 representasse um ponto de apogeu na vida do poeta". E, adiante, acrescenta: "Marx, que de rapaz havia sonhado em vão com cingir em sua cabeça o laurel da poesia, guardou sempre uma viva simpatia pelo grêmio dos poetas e uma grande indulgência para suas pequenas debilidades. Entendia que os poetas eram seres raros a quem se devia deixar marchar livremente pela vida, e que não se lhes podia medir da mesma forma que aos outros homens; não havia mais remédio que mimá-los um pouco, se se queria que cantassem; com eles não valiam as críticas severas. Porém, em Heine Marx não via só o poeta, senão que via também o lutador." (MEHRING, 1975, , p. 90) 
afirmar: "Dizem que os espíritos noturnos ficam aterrorizados quando avistam a espada de um carrasco. -Quanto não ficariam aterrorizados se se lhes apresentasse a Crítica da razão pura de Kant! Esse livro é a espada com que se executou o deísmo na Alemanha." (HEINE, 1991, p. 89) ${ }^{7}$

Talvez haja algum exagero dramático na verve poética de Heine, porém, o movimento filosófico que conduz de Kant a Feuerbach não pode ter passado despercebido a Marx, que tampouco deve ter permanecido infenso às ideias de Heine, apesar das escassas e superficiais referências a Kant ao longo de sua obra. O grandioso projeto de crítica da economia política parece não estar assim tão longe (até porque eminentemente crítico) da influência kantiana ${ }^{8}$. Em todo caso, Marx parece concordar, àquela época, com a estimativa de Heine sobre a importância da revolução filosófica operada na Alemanha ${ }^{9}$, tendo como ponto culminante Hegel, inclusive por sustentar que a crítica da religião precede toda crítica, e que esta já teria sido efetuada na Alemanha. Em seu trabalho anterior para a mesma publicação, Zur Judenfrage, Marx já defende a tese de que o fenômeno religioso deve ser interpretado à luz do contexto social em que está inserto, incluindo-se aí suas consequências políticas. No artigo introdutório à crítica da filosofia do direito de Hegel, Marx, nas pegadas de Feuerbach, afirma que é o homem que faz a religião, e não o contrário, e que esta, como consciência invertida do mundo, deve ser desmascarada.

7 Em 1835, este livro de Heine foi publicado na França sob o título de Allemagne, em alusão crítica à obra homônima de Madame de Staël.

8 Sem querer adentrar na temática da relação entre os pensamentos de Kant e Marx, que ultrapassaria amplamente os limites deste exercício, seria conveniente recordar, apenas en passant, que J indrich Zeleny, em seu importante trabalho sobre O capital, chega a afirmar que "O 'criticismo' prático e histórico de Marx tem novas dimensões: porém na história dos problemas a conexão com a crítica kantiana da razão parece essencial" (ZELENY, 1974 , p. 311). O que se daria por meio da temática comum da liberdade, já que para Zeleny "O eixo que unifica todo o período revolucionário filosófico que vai de Kant a Marx é o problema da liberdade humana, ou da libertação humana" (ZELENY, 1974 , p. 310). Ademais, caberia ainda recordar a existência de indicações de que, ao final de sua vida, Marx nutria um projeto de estudos em que Kant estava incluído. Segundo o depoimento de Voder acerca das conversações que manteve com Engels em 1893, este lhe teria confidenciado o seguinte: "Também fez [Engels] referência a que Marx havia tido a intenção de prosseguir seus estudos sobre história da filosofia grega, e que também durante seus últimos anos mantinha alguma conversa com ele sobre este tema, sem demonstrar nenhuma predileção pelo sistema materialista, senão que aprofundando sobretudo na dialética platônica e aristotélica. Entre os filósofos modernos havia demonstrado um interesse especial por Leibniz e Kant." (ENZENSBERGER, 1972, t. II, p. 586) Aliás, Kant foi uma das fontes de inspiração de Marx em sua juventude, a cuja influência esteve submetido antes que se dedicasse ao estudo de Hegel. Segundo seu próprio depoimento, no final de 1837, "Abandonado o idealismo que, dito seja de passagem, havia cotejado e nutrido com o de Kant e Fichte, dediquei-me a buscar a ideia na realidade mesma" (MARX, 1982b, p. 10).

9 Heine afirma, por exemplo: "A filosofia alemã é uma questão importante que diz respeito a todo o gênero humano, e apenas nossos futuros descendentes poderão decidir se devemos ser louvados ou censurados por concluirmos, primeiro, a nossa filosofia e, apenas depois, a nossa revolução." (HEINE, 1991, p. 127) 
Enfim, Marx reafirma a assertiva vigente nos meios do "hegelianismo jovem" de que "A religião é o ópio do povo" (MARX, 1982a, p. 491; 1959a, p. 208).

\section{1. “ópio do povo”}

A nomeada da assertiva exige uma consideração mais detida. Não é unívoca a atribuição de sua disseminação no interior do movimento jovem-hegeliano. Há quem a credite a David Strauss ou a Bruno Bauer; o fato, porém, é que sua extraordinária divulgação deveu-se, sobretudo, a $\operatorname{Marx}^{10}$. Com efeito, a lapidar denúncia da religião como "ópio do povo" assumiu o status de um bordão, que passa a ter vida própria, independente do contexto original em que foi pronunciada. Apesar da preeminência da crítica religiosa, Marx não acredita que ela se resolva em si mesma. Em ambos os artigos do Deutsch-Französische Jahrbücher Marx remete a questão religiosa para o plano da sociedade civil. Para que a ilusão religiosa se dissolva é necessário transformar a realidade social em um sentido tal que ela se torne desnecessária. "A crítica do céu se converte com isso em crítica da terra, a crítica da religião em crítica do direito, a crítica da teologia em crítica da política." (MARX, 1982a, p. 492; 1959a, p. 209) A filosofia, enquanto crítica, não se realiza, contudo, para Marx, sem que o proletariado, força material da história, a efetive. Em suas palavras:

Assim como a filosofia encontra no proletariado suas armas materiais, o proletariado encontra na filosofia suas armas espirituais, e tão pronto como o raio do pensamento cale fundo neste candoroso solo popular, a emancipação dos alemães como homens será efetivada. (...) A filosofia não pode chegar a se realizar sem a abolição do proletariado, e o proletariado não

10 Para J osé Crisóstomo de Souza, "Foi Strauss (...) quem primeiro formulou, em 1837, a classificação dos hegelianos em 'esquerda', 'direita' e 'centro'. E, aliás, teria sido também quem introduziu, na linguagem do grupo, a expressão 'ópio do povo', popularizada depois por Marx" (SOUZA, 1992, p. 14). Já segundo David MacLellan, "A famosa metáfora do ópio do povo foi também antecipada por Bauer em seu livro Die gute Sache der Freiheit, no qual se refere a como a religião 'na estupefação semelhante à do ópio de sua excitação destrutora, fala de uma vida futura em que tudo se fará novo', e também em Der christliche Staat da 'influência semelhante à do ópio' da teologia sobre o gênero humano, ainda que a expressão fosse muito usada por muitos dos jovens hegelianos, que podem muito bem havêla tomado da descrição de Hegel da religião indiana" (MACLELLAN, 1971, p. 93). Em favor de J osé Crisóstomo está o fato de os trabalhos de Bauer, citados por MacLellan, serem de 1842 e 1841, respectivamente, o que poderia conferir a precedência a Strauss na divulgação da assertiva. Entretanto, não é necessário que as afirmações de ambos os autores se contraponham, o que testemunharia uma aceitação mais ou menos ampla nos meios jovem-hegelianos daquilo que depois se converteu em palavra de ordem atribuída a Marx. Ademais, como sustenta MacLellan, ao examinar a religião hindu, Hegel utiliza metáfora assemelhada; para ele "a religiosidade dos indianos é um sonho", está fundada na "embriaguez da fantasia" (HEGEL, 1974, p. 309); claro está que Hegel não estenderia tal afirmação ao cristianismo, sobretudo em sua versão protestante. 
pode chegar a se abolir sem a realização da filosofia. (MARX, 1982a, p. 502; 1959a, pp. 223-4)

Na medida em que está despossuído de propriedade privada, a emancipação do proletariado coincide com "a dissolução da ordem universal" nela fundada, recuperando a essência humana"11, como se verá adiante, alienada no dinheiro. Quem pode iluminar este caminho revolucionário é o filósofo, que vislumbra a verdadeira natureza do homem.

A despeito deste contexto teórico, a assertiva da religião como "ópio do povo" tendeu a ser interpretada como um grito de guerra frontal, como uma cruzada contra o entorpecimento da consciência popular. As políticas religiosas dos estados onde imperou o chamado "socialismo real" servem para exemplificar como foi consumada a interpretação prática do bordão. Ainda que formal e juridicamente mais ou menos toleradas, as religiões foram combatidas e substituídas por uma exagerada deferência às lideranças políticas, num fenômeno comumente denominado de "culto à personalidade". O deprimente espetáculo das romarias ao corpo embalsamado de Lênin ilustra este fenômeno, cuja ironia reside na substituição das religiões, enquanto tais, por uma idolatria dos próceres revolucionários, elevados à categoria de heróis, no sentido mítico do termo. O fato é que a animosidade recíproca entre o movimento político de inspiração marxista e as confissões religiosas encontrou na palavra de ordem da religião como "ópio do povo" respaldo teórico. Enquanto projeção humana, epifenômeno ideológico, a religião seria superada pela crítica racional (pela filosofia), a verdade suplantaria o engodo e, enquanto "ópio do povo", instrumento da dominação classista, da subjugação ideológica, seria materialmente combatida pela ação prática, o que conjugaria a filosofia e o proletariado na tarefa comum libertária, emancipatória. Esta iconoclastia é disseminada pelo bordão em duas vertentes, pela denúncia frontal da falsidade religiosa e pelo combate à persistência de suas práticas.

Em que pese o desdobramento histórico ulterior, mesmo neste desenvolvimento teórico precoce, anterior ao projeto de crítica da economia política, Marx já se precata de que a "ilusão" religiosa não se desvanece sem uma revolução nas condições práticas de existência do homem, coisa que o "socialismo real" não pôde efetivar. Para que o "candoroso solo popular" se deixasse realmente fecundar pela semente

11 "Quando o proletariado proclama a dissolução da ordem universal anterior, não faz mais que apregoar o segredo de sua própria existência, já que ele é a dissolução de fato desta ordem universal. Quando o proletariado reclama a negação da propriedade privada, não faz mais que elevar a princípio da sociedade o que a sociedade elevou a princípio seu, o que já nele se personifica, sem intervenção sua, como resultado negativo da sociedade." (MARX, 1982a, p. 502; 1959a, p. 223) 
revolucionária, ou seja, pela filosofia, que em sua realização prometeria a redenção da humanidade, seria preciso denunciar o desvio, a "alucinação" provocada pela soteriologia religiosa. Sabendo-se, de antemão, que seu efeito "entorpecente" só cessaria com o fim da propriedade privada e do dinheiro, "a divindade visível" [die sichtbare Gottheit] ${ }^{12}$, objetivação da essência humana alienada, o plano de combate da coligação filosofia/proletariado assumiria os contornos de um confronto com a burguesia, em todos os níveis, pelo fim da propriedade privada e da dominação burguesa dos pontos de vista prático e teórico. Todavia, não há decreto que possa extinguir, de um canetaço, a religiosidade, sem levar com ela as condições sociais que a fizeram emergir. Ainda que de modo impreciso, a religiosidade, para Marx, já neste primeiro momento não é um mero epifenômeno ideológico superficial, cujo simples esclarecimento permitisse superar.

A enorme acolhida e a ampla disseminação da emblemática assertiva da religião como "ópio do povo", per se, mereceriam um estudo específico, impossível de ser efetuado aqui. Restaria, contudo, constatar que, ao ser despojado de seu contexto discursivo, o bordão adquire um significado próprio, que certamente ultrapassa o das circunstâncias conjunturais em que foi enunciado, relevantes num artigo apenas introdutório e, sobretudo, tendo como objetivo central a polêmica, em que as frases de efeito, pela sedução retórica, não deixam de ser apreciadas. Qualquer que seja a razão, o fato é que a disseminação da palavra de ordem traz em seu bojo, explícita ou sub-repticiamente, a ideia de resolução do enigma religioso, cujo significado estaria perfeitamente dilucidado, uma vez proclamada sua etiologia no social. A "ilusão" que desta forma se desvaneceria, como o efeito entorpecente na abstinência da droga sugerido pela metáfora, parece conduzir à imediata caracterização da religiosidade como um epifenômeno ideológico, "reflexo", utilizando um termo muito apreciado por Lênin, da organização social, ou de suas condições materiais. Assim, a problemática religiosa, dissolvida no social ou no econômico, estaria perfeitamente decifrada e, portanto, resolvida. Uma vez instalado o proletariado no poder, a religiosidade estaria com seus dias contados. Se esta não é exatamente a posição de Marx, nem sequer em seus primeiros trabalhos, não há dúvida de que, para ele, o canto revolucionário do galo francês, que despertaria a revolução alemã, já estava prestes a soar.

12 Parafraseando Shakespeare, Marx denomina o dinheiro de "a divindade visível [die sichtbare Gottheit]" (cf. MARX, 1982c, p. 643; 1959b p. 299). 


\subsection{A "divindade visível"}

Conviria, não obstante, examinar agora Zur J udenfrage, o primeiro artigo de Marx para o Deutsch-Französische Jahrbücher. Marx termina este trabalho, em que polemiza com Bruno Bauer, concluindo que "A emancipação dos judeus" coincidiria, "em última instância", com a "emancipação da humanidade do judaísmo" (MARX, 1982d, p. 486; 1959c, p. 202) ${ }^{13}$, que, em sua expressão laica, significaria a abolição da usura e do dinheiro. Com efeito, para ele, o judaísmo, em sua expressão secular - já que não se deve buscar "o mistério do judeu em sua religião, senão (...) o mistério da religião no judeu real" (MARX, 1982d, p. 495; 1959c, p. 201) - , não seria outra coisa que o egoísmo feito religião, com seu culto prático ao dinheiro, cujo clímax é atingido na sociedade burguesa, quando esta "religião" se universaliza. Para Marx, "O dinheiro é o ciumento Deus de Israel, ante o qual não pode legitimamente prevalecer nenhum outro Deus. $\mathrm{O}$ dinheiro humilha a todos os deuses do homem e os converte em mercadoria". E logo adiante acrescenta: "O dinheiro é a essência do trabalho e da existência do homem, dele alienada, e esta essência estranha o domina e é adorada por ele. O Deus dos judeus secularizou-se, converteu-se em Deus universal." (MARX, 1982d, pp. 487-8; 1959c, p. 204) Com isto, Marx já se havia afastado da caracterização abstrata da religião efetuada por Feuerbach. Os cultores do "judaísmo" não estariam apenas nas sinagogas, mas o cristianismo, oriundo do judaísmo, "voltou a dissolver-se nele" (MARX, 1982d, p. 489; 1959c, p. 206). "Não é, portanto, no Pentateuco ou no Talmude, senão na sociedade atual, que encontramos a essência do judeu de hoje, não como um ser abstrato, senão como um ser altamente empírico, não só como a limitação do judeu, senão como a limitação judaica da sociedade." (MARX, 1982d, pp. 489-90; 1959c, p. 207) Em Marx, a abstrata antropologia feuerbachiana encontra uma expressão prática na alienação do dinheiro, que incorpora a "essência do trabalho e da existência do homem", despojando-o de seu conteúdo, esvaziando-o, tomando para si (dinheiro) a representação das potencialidades humanas, seus atributos.

Já em 1843, portanto, Marx começa a esboçar o tema central de toda sua obra, o desvendamento do enigma da sociedade burguesa, e principia a direcionar-se para a alienação do homem, ser genérico [Gattungswesen] ${ }^{14}$ tornado indivíduo, movido pelo egoísmo e estranhado

13 Na última frase do artigo Marx repete a assertiva, reafirmando que "a emancipação social do judeu é a emancipação da sociedade do judaísmo" (MARX, 1982d, p. 490; 1959c, p. 207).

14 "Só quando o homem individual real recobra em si o cidadão e se converte, como homem individual, em ser genérico [Gattungswesen], em seu trabalho individual e em suas relações individuais; só quando o homem reconhece e organiza suas 'forces propes' 
de si mesmo pelos produtos de seu próprio trabalho que, enquanto mercadorias e enquanto representados como dinheiro e sob esta forma cultuados como forças alheias ao homem, na prática o subjugam como algo que se lhe apresenta como externo, transcendente, como Deus. Marx percebe que a vitória sobre o demiurgo prático do dinheiro não pode ser lograda apenas pelo esclarecimento, a "ilusão" religiosa não pode ser desfeita sem que para isto concorra uma profunda revolução que unifique num só movimento a filosofia e o proletariado. Por isto afirma, pouco tempo depois, em 1845, em suas Thesen über Feuerbach, que "em A essência do cristianismo só se considera autenticamente humano o comportamento teórico, e em troca a prática só se capta e se plasma sob sua suja forma judia de se manifestar. Daí que Feuerbach não compreenda a importância da atividade revolucionária, da atividade crítico-prática" (MARX, 1974b, pp. 665-6; 1959d, p. 339).

Para Marx, contudo, a superação da religiosidade só pode ser mediata, por meio da supressão das condições sociais de existência que lhe dão sustentação. A unidade revolucionária da filosofia e do proletariado só conseguirá desvanecer definitivamente o véu religioso pela transformação revolucionária da sociedade, com o fim da propriedade privada e do estranhamento do homem em relação aos produtos do seu próprio trabalho, com o fim da mediação hipostasiada do dinheiro, "a divindade visível". Parece haver, portanto, mesmo neste desenvolvimento teórico precoce, pela relação entre a divindade e o dinheiro, uma estimativa de que a religiosidade não é uma "superestrutura" [Überbau] facilmente descartável ${ }^{15}$. Pelo contrário, a remoção do véu religioso está ligada à supressão das condições sociais que lhe deram origem, vale dizer, pela revolução stricto sensu, ou seja, pela revolução comunista, que subverta completamente as relações sociais, extinguindo a propriedade privada e o dinheiro, enfim, o conjunto das relações mercantis, instrumentos da dominação dos burgueses sobre os proletários. A importância que Marx confere à questão religiosa pode ser mais bem apreendida quando se recorda que o discurso crítico de Marx começa precisamente ali onde Feuerbach se detém. A crítica da religião inaugura toda crítica. Contudo, uma vez concluída, e Marx assim a considera na Alemanha, há que se

como forças sociais e quando, portanto, não separa já de si a força social sob a forma de força política, só então se leva a cabo a emancipação humana." (MARX, 1982d, p. 484; 1959c, p. 199)

15 Aliás, esta metáfora construtiva parece-me singularmente simplória. Muito já se discutiu sobre esta questão e não me parece produtivo prosseguir. Além de estática, a metáfora obnubila o fato de que as ideias podem exercer um "poder material". Ou, nas próprias palavras de Marx: "É certo que a arma da crítica não pode substituir a crítica das armas, que o poder material tem de se derrubar por meio do poder material, porém a teoria se converte em poder material [grifo nosso, M.M.] tão pronto se apodere das massas." (1982a, p. 497; 1959a, p. 216) 
partir daí, transpor o plano teórico e chegar à prática, esfera em que a vida verdadeiramente se decide. A ingente tarefa teórica de Marx inicia-se, portanto, aí, no ponto em que a antropologia feuerbachiana chega a seu termo.

Sob a influência dos artigos de Engels e de Moses Hess para o Deutsch-Französische J ahrbücher ${ }^{16}$, Marx envereda pela longa trajetória teórica que caracterizará a melhor e mais original parcela de sua extensa produção intelectual, legado imperecedouro, que deixa marca indelével para a posteridade. Etapa que se inicia com os Manuscritos de 1844, cuja pretensão teórica não se restringe apenas aos domínios daquilo que usualmente se costuma denominar de economia política, mas objetiva tender uma ponte entre esta disciplina desenvolvida por ingleses e, em menor medida, pelos franceses, e os temas relativos a estado, direito, moral e vida burguesa em geral. Como assinala Cornu:

Para que seja eficaz, a luta contra a religião deve transformar-se num combate contra a sociedade que a produz. Combater a religião e suas promessas de uma felicidade ilusória reduz-se, em realidade, a criticar e abolir as condições sociais que engendram a ilusão religiosa, satisfazer efetivamente as necessidades dos homens e reivindicar para eles a felicidade na terra. (CORNU, 1976, p. 413)

Tal concepção desloca a atenção precípua de Marx para o estudo da economia política, cujo discurso é visto como a expressão mais bem concatenada da sociedade burguesa e dos interesses por ela ensejados ${ }^{17}$. Uma vez concluída a crítica da religião, que não se resolve em si mesma, é necessário, consequentemente, proceder à crítica da economia política, discurso que dá a chave para a compreensão e transformação da realidade

16 Engels, com seu artigo Umrisse zu einer Kritik der Nationalökonomie, aliás sempre encomiado por Marx, o antecede, despertando-o para a crítica da economia política. Já Moses Hess, em seu artigo Über das Geldwesen (publicado no Reinische J ahrbücher zur gesellschsftlichen Reform, mas que estava originalmente destinado à revista dirigida por Ruge e Marx e que, portanto, Marx não podia desconhecer), segundo a opinião de Cornu, "desenvolvia numerosas ideias sobre a essência do dinheiro, os direitos do homem, o caráter e o papel das corporações e dos 'estados', que também se encontram nos escritos de Marx de então, coisa que sem dúvida se explica por suas estreitas relações em Paris, o que lhes permitiu intercambiar ideias" (CORNU, 1976, t. II, pp. 487-8). Talvez um dos pontos centrais das teses de Hess seja sua afirmação de que "Deus é para a vida teórica o mesmo que o dinheiro para a vida prática" (HESS, 1980, p. 334).

17 "Para deixar bem claro de uma vez por todas, digamos que entendo por economia política clássica toda a economia que, desde William Petty, investigou a conexão interna das relações de produção burguesas, por oposição à economia vulgar, que não faz mais que perambular de modo estéril em tomo da conexão aparente, preocupando-se só em oferecer uma explicação óbvia dos fenômenos que poderíamos chamar de mais vastos e ruminando uma e outra vez, para o uso doméstico da burguesia, o material subministrado faz já tempo pela economia científica. Mas, além disso, nesta tarefa a economia vulgar se limita a sistematizar de maneira pedante as ideias mais triviais e vazias formadas pelos membros da burguesia acerca de seu próprio mundo, o melhor dos possíveis, e proclamálas como verdades eternas." (MARX, 1974a, p. 99; 1972a, p. 95) 
social capitalista, conditio sine qua non para que a crítica da religião implemente-se de fato, satisfazendo os legítimos anseios populares de justiça, religiosamente expressos. Daí o giro teórico, que termina por distanciar Marx da antropologia feuerbachiana, transportando-o da crítica da religião para a crítica do suporte da própria religiosidade, para a crítica da realidade social que a engendra e cuja expressão teórica mais acabada manifesta-se na economia política, o discurso par excellence da sociedade burguesa. É por esta razão que Marx, já em 1844, afirma:

Partimos das premissas da economia política. Aceitamos sua linguagem e suas leis. Demos por supostos a propriedade privada, a separação do trabalho, do capital e da terra, e ainda, o salário, o lucro do capital e a renda do solo, a divisão do trabalho, a competição, o conceito de valor de troca etc. Partindo da própria economia política e com suas mesmas palavras, demonstramos que o operário degenera em mercadoria [grifo nosso, MM] (...). A economia política parte da propriedade privada como fato. Mas não o explica. Capta o processo material da propriedade privada, que esta percorre na realidade, em formas gerais e abstratas, que logo considera leis. Contudo, não compreende estas leis ou, dito de outro modo, não demonstra como brotam da essência da propriedade privada. A economia política não nos oferece uma explicação do fundamento sobre o qual repousa a divisão entre trabalho e capital e entre o capital e a terra. (MARX, 1982c, pp. 594-5; 1972c, p. 56) $)^{18}$

Em seguida, Marx discorre amplamente sobre a alienação, que é, segundo sua perspectiva da época, o núcleo central daquilo que o discurso da economia política omite, ou seja, o que o discurso burguês não pode revelar. A crítica da economia política emerge, a partir daí, como o tema central da obra teórica de Marx e, neste primeiro momento, a alienação [Entfremdung] é a categoria sobre a qual fundamenta tal crítica. É por este meio que Marx começa a abordar a temática do processo de subordinação real dos homens às coisas, ou a outros homens, pela mediação das coisas, pela conversão dos homens em objetos submetidos aos produtos de seu próprio trabalho. Em suas palavras:

Na medida em que se valoriza o mundo das coisas, desvalorizase, em razão direta, o mundo dos homens. O trabalho não

18 O projeto de crítica da economia política deveria avançar, também, na direção da crítica da "mercadoria" "força de trabalho", conforme, ademais, parece insinuado pela passagem grifada. Embora Marx parta do próprio discurso da economia política, aceitando-lhe as premissas, para revelar suas contradicões internas, a transformação de homens em mercadorias não tem nada de trivial. Ainda com respeito ao trecho citado, seria oportuno acrescentar que ele corrobora a assertiva de István Mészáros, quando este declara: "Marx deixou claro, mais de uma vez, em seus Manuscritos de 1844, que toma como ponto de partida a linguagem da economia política para resgatar suas realizações, que permaneciam ocultas aos próprios economistas políticos, bem como para criticá-los em seus próprios termos." (MÉSZÁROS, 1981, p. 198) 
produz somente mercadorias; produz-se também a si mesmo e produz o operário como mercadoria, e, além do mais, na mesma proporção em que produz mercadorias em geral. O que este fato expressa é, simplesmente, o seguinte: o objeto produzido pelo trabalho, seu produto, enfrenta-se com ele como algo alheio, como uma força independente do produtor. $\mathrm{O}$ produto do trabalho é o trabalho plasmado em um objeto, convertido em coisa, é a objetivação [Vergegenständlichung] do trabalho. A realização do trabalho é sua objetivação. Esta realização do trabalho, tal e como se apresenta na economia política, aparece como desrealização [Entwirklichung] do trabalhador, a objetivação se manifesta como perda e servidão materiais, a apropriação como alienação [Entfremdung], como estranhamento [Entäußerung]. (MARX, 1982c, p. 596; 1972d, pp. 57-8)

E mais adiante conclui:

Todas estas consequências vêm determinadas pelo fato de que o operário se comporta com relação ao produto de seu trabalho como frente a um objeto alheio. Com efeito, partindo desta premissa resulta claro que quanto mais o operário se mata trabalhando, mais poderoso se torna o mundo material alheio que ele cria diante de si, mais pobres se tornam ele e seu mundo interior, menos se pertence o operário a si mesmo. O mesmo sucede na religião. Quanto mais põe o homem em Deus, menos retém de si mesmo. (MARX, 1982c, p. 596; 1972d, pp. 57-8)

O trabalho humano, enquanto tal, contudo, não engendra alienação, só o trabalho alienado o faz. O trabalho, per se, não subjuga o homem a seus produtos, pelo contrário, enquanto "atividade vital" é produto e garantia da differentia specifica do homem, fruto de sua atividade livre e consciente, que faz dele o que é. Para Marx, o homem universaliza-se na medida em que, enquanto homem, pelo seu trabalho, converte a natureza em seu corpo $^{19}$, perdendo esta qualidade de ser genérico, quando se aliena. "Toda autoalienação do homem com respeito a si mesmo e à natureza se revela na medida em que se entrega e entrega a natureza a outro homem distinto dele." (MARX, 1982c, p. 602; 1972d, p. 66) Ao ceder a outro o produto do seu trabalho, o homem abdica desta força que lhe é constitutiva, o trabalho, alienando seu ser genérico, esta universalidade que dormita em sua capacidade ilimitada de integrar porções da realidade natural a seu ciclo social reprodutivo, não apenas no sentido smithiano,

19 "A universalidade do homem manifesta-se cabalmente, na prática, pela universalidade com que converte toda a natureza em seu corpo inorgânico (...). Dizer que o homem vive da natureza significa que a natureza é seu corpo, com o qual se deve manter em relação constante para não morrer. A afirmação de que a vida física e espiritual do homem encontra-se entrelaçada com a natureza não tem outro sentido além daquele de que a natureza está entrelaçada consigo mesma, pois o homem é parte da natureza." (MARX, 1982c, pp. 599-600; 1972d, p. 62) 
como productive powers of labour ${ }^{20}$, mas como um ser que desconhece as limitações dos outros animais ${ }^{21}$ e que, enquanto parcela da natureza, pode integrá-la consciente e reflexivamente a si mesmo.

\section{Referências bibliográficas}

CORNU, Auguste. Carlos Marx, Frederico Engels. Trad. Ana Faya. Havana: Ed. de Ciencias Sociales, 1976. 4 t.

ENZENSBERGER, Hans Magnus. Conversaciones con Marx y Engels [epistolário]. Trad. de Michel Faber-Kaiser. Barcelona: Anagrama, 1972. 2 t.

FEUERBACH, Ludwig. La esencia del cristianismo. Trad. Franz Huber. México: J uan Pablos, 1972.

HEGEL, F. W. Lecciones sobre la filosofía de la historia universal. Trad. J osé Gaos. Madri: Revista del Occidente, 1974.

HEINE, Heinrich. Contribuição à história da religião e filosofia na Alemanha. Trad. Márcio Suzuki. São Paulo: Iluminuras, 1991.

HESS, Moses. “Über das Geldwesen”. In: Philosophische und sozialistische Schriften (1837-1850) [compilação]. Vadus: Topos, 1980.

MACLELLAN, David. Marx y los jóvenes hegelianos. Trad. Marcial Suárez. Barcelona: Martínez Roca, 1971.

MARX, Karl. "Zur Kritik der Hegelschen Rechtsphilosophie Einleitung”. In: Die Frühschriften. Stuttgart: Alfred Kröner, 1959a.

. "Nationalökonomie und Philosophie". In: Die Frühschriften.

Stuttgart: Alfred Kröner, 1959b.

"Zur Judenfrage". In: Die Frühschriften. Stuttgart: Alfred Kröner, 1959c.

. Die Frühschriften. Stuttgart: Alfred Kröner, 1959d.

. Das Kapital, I, MEW, t. 23. Berlim: Dietz, 1972a.

Manuscritos económico-filosóficos. Trad. Wenceslao Roces. México: Grijalbo, 1972b.

. Euvres économie (ed. prep. Maximilien Rubel). Paris: Gallimard, 1972c. 2 t.

20 Com o conceito de forças produtivas, largamente utilizado pela tradição marxista, pretende-se fazer referência à maior ou menor capacidade que tem o trabalho humano, nos diversos períodos históricos, de incorporação de matérias naturais ao ciclo social reprodutivo humano.

21 "O animal forma uma unidade imediata com sua atividade vital. Não se distingue dela. É ela. O homem faz de sua própria atividade vital o objeto de sua vontade e de sua consciência. Desenvolve uma atividade vital consciente. Não é uma esfera determinada com a que se funda diretamente. A atividade vital consciente distingue o homem diretamente da atividade vital dos animais. E isto é precisamente o que faz dele um ser genérico." (MARX, 1982c, p. 600; 1972d, p. 63) 
. "Économie et philosophie". In: Euvres économie (ed. prep. Maximilien Rubel). Paris: Gallimard, 1972d, t. II.

. El capital l. I, v. 1. Trad. Wenceslao Roces. México: Fondo de Cultura Económica, 1974a. 3 v. 8 t.

. "Tesis sobre Feuerbach". In: ; ENGELS, F. La ideología alemana [Apêndice]. Trad. Wenceslao Roces. México: Ediciones de Cultura Popular, 1974b.

. "En torno a la crítica de la Filosofía del derecho de Hegel, Introducción". In: Escritos de juventud. Trad. Wenceslao Roces. México: Fondo de Cultura Económica, 1982a.

. "Carta ao pai de 10 de novembro de 1837". In: Escritos de juventud. Trad. Wenceslao Roces. México: Fondo de Cultura Económica, 1982b.

. "Manuscritos económico-filosóficos de 1844". In: Escritos de juventud. Trad. Wenceslao Roces. México: Fondo de Cultura Económica, 1982c.

. "Sobre la cuestión judía". In: Escritos de juventud. Trad. Wenceslao Roces. México: Fondo de Cultura Económica, 1982d.

. Escritos de juventud. Trad. Wenceslao Roces. México: Fondo de Cultura Económica, 1982e.

; ENGELS, F. La ideología alemana. Trad. Wenceslao Roces. México: Ediciones de Cultura Popular, 1974.

MEHRING, Franz. Carlos Marx: historia de su vida. trad. Wenceslao Roces. Barcelona: Grijalbo, 1975.

MÉSZÁROS, István. Marx: a teoria da alienação. Trad. Waltensir Dutra. Rio: Zahar, 1981.

SOUZA, J osé C de. Ascensão e queda do sujeito no movimento jovemhegeliano. Salvador: EdUfba, 1992.

ZELENY, Jindrich. La estructura lógica de El capital de Marx. Trad. de Manuel Sacristán. Barcelona: Grijalbo, 1974.

Como citar:

MOURA, Mauro Castelo Branco. Marx e a crítica da religião. Verinotio Revista on-line de Filosofia e Ciências Humanas, Rio das Ostras, v. 24, n. 2, pp. 115-127, nov. 2018.

Data de envio: 13 mar. 2018

Data de aceite: 19 maio 2018 